\title{
Vale o quanto Custa? Um Estudo sobre a Relação entre a Capacidade Institucional dos Tribunais de Contas Subnacionais Brasileiros e a Qualidade das Políticas Públicas de seus Respectivos Estados
}

\author{
Worth What It Costs? A Study on the Relationship between the Institutional \\ Capacity of the Brazilian Subnational Accounts Courts and the Quality of Public \\ Policies of their Respective States
}

\section{Thiago Augusto de Oliveira Marinho Ferreira ${ }^{1}$ \\ Universidade Federal de Pernambuco, Brasil}

\begin{abstract}
RESUMO O controle é um ato ou momento político central de um ciclo mais amplo da representação democrática. Para assegurar que os representantes, uma vez à frente de seus cargos, pautem sua conduta pelo "melhor interesse de seus representados", é necessário haver instrumentos efetivos e continuados de controle. No Brasil, a Constituição Federal conferiu aos Tribunais de Contas o desafio de controlar suas contas públicas. Mas qual é a relação entre o fortalecimento do controle dos gastos públicos - a partir de uma maior capacidade institucional destes órgãos de controle - e a qualidade das políticas públicas oferecidas aos cidadãos? O presente artigo se propõe a investigá-la. Para tanto, o desenho de pesquisa combina estatística descritiva e multivariada para analisar um banco de dados original elaborado com informações obtidas de diferentes fontes. Em particular, operacionaliza-se a capacidade institucional dos
\end{abstract}

1. Doutor e Mestre em Ciência Política, Universidade Federal de Pernambuco - UFPE. Email: thiago.aomf@hotmail.com. O autor agradece as valiosas ponderações dos professores da UFPE e, em especial, às significativas sugestões e recomendações propostas pelos avaliadores anônimos. Quaisquer incorreções remanescentes são de sua total responsabilidade. 
Tribunais de Contas subnacionais brasileiros a partir das seguintes variáveis: orçamento, pessoal e contas julgadas irregulares. Não obstante, utiliza-se a análise fatorial para definir os indicadores relativos à qualidade das políticas públicas de saúde e educação de seus respectivos Estados, no ano de 2010. Dentre as variáveis analisadas, os resultados preliminares sugerem que o fortalecimento do controle dos gastos públicos está positivamente correlacionado com a qualidade das políticas públicas oferecidas aos cidadãos.

PALAVRas-CLave Tribunais de Contas, Capacidade Institucional, Políticas Públicas.

ABSTRACT Control is a central political act or moment of a broader cycle of democratic representation. To ensure that representatives, once at the head of their positions, conduct themselves in the "best interests of their constituencies", there must be effective and continuous instruments of control. In Brazil, the Federal Constitution gave the Audit Courts the challenge of controlling their public accounts. But what is the relationship between strengthening public spending control - based on a greater institutional capacity of these control bodies - and the quality of public policies offered to citizens? This article proposes to investigate it. To do so, the research design combines descriptive and multivariate statistics to analyze an original database prepared with information obtained from different sources. In particular, the institutional capacity of the Brazilian subnational Accounts Courts is operationalized based on the following variables: budget, personnel and accounts judged to be irregular. $\mathrm{Ne}$ vertheless, the factorial analysis is used to define the indicators related to the quality of the public health and education policies of their respective States, in 2010. Among the variables analyzed, the preliminary results suggest that the strengthening of the control of public expenditures is positively correlated with the quality of public policies offered to citizens.

KEYWORDS Courts of Accounts, Institutional Capacity, Public policy.

\section{Introdução}

O debate sobre instituições de controle tornou-se mais presente nas últimas décadas - principalmente - em razão da consolidação das democracias. Afinal, o controle sobre a Administração Pública é dimensão crucial de uma ordem democrática² ${ }^{2}$.

2. ARANTES et al. (2011). 
No Brasil, a população é confrontada quase que diariamente com temas relacionados ao controle dos gastos públicos que tem ocupado grande espaço na mídia e no debate público ao longo dos últimos anos. De um lado, há denúncias de escândalos envolvendo agentes públicos e do poder privado - é cotidiano aparecerem casos de grandes "esquemas" que desviaram sistematicamente recursos milionários dos cofres públicos. De outro, a preocupação com o bom uso dos recursos públicos também é oriunda da inquietação do poder público com o tema - o esgotamento fiscal do Estado brasileiro forçou os governos a redirecionarem os seus esforços de desenvolvimento para o horizonte da eficiência, da eficácia e da efetividade, de modo a compeli-los a fazer melhor aquilo que fazem com os recursos já existentes, ou até com menos do que isso.

E é nesse contexto em que se observa a grande razão para este crescente interesse pelo estudo das instituições de controle. Notadamente pelo papel que podem desempenhar não só no combate à corrupção, mas também na redução de desperdícios e na melhoria da responsabilização dos governos, que são objetivos-chave da governança democrática ${ }^{3}$.

Com efeito, os instrumentos de controle da Administração Pública desenvolvidos pelo Brasil pós-1988 envolvem desde o controle parlamentar, exercido pelo Legislativo sobre o Executivo, os controles judiciais, os controles administrativos e financeiros e diferentes formas de controle social. Dentre estes, importa destacar os controles administrativos e financeiros exercidos pelos Tribunais de Contas, que possuem a função de verificar se o poder público efetuou as despesas da maneira como fora determinado pelo orçamento e pelas normas legais mais gerais (tais como: os limites para endividamento, a vinculação orçamentária a determinadas áreas, etc). O ponto central dessa fiscalização é a probidade, tendo como finalidade não permitir o mau uso dos recursos públicos ${ }^{4}$.

Os Tribunais de Contas surgiram historicamente com a República, sendo concebidos como órgãos de assessoria técnica do Legislativo em sua atividade de controle das contas públicas - hoje, existem 33 Tribunais de Contas em funcionamento no país. A Constituição de 1988 assegurou a eles uma série de avanços institucionais, ao passo que a Lei de Responsabilidade Fiscal (Lei Complementar $n^{\circ}$ 101/2000) ampliou suas funções fiscalizatórias, materializando a preocupação do legislador com a qualidade da gestão fiscal dos recursos públicos ${ }^{5}$ e, mais recentemente, a Lei da Ficha Limpa (Lei Complementar $n^{\circ} 135 / 2010$ ) conferiu um peso maior às suas decisões.

3. MELO et al. (2009).

4. Idem.

5. ARANTES et al. (2005); ROCHA et al. (2014). 
Contudo, embora se tratem de instituições de longa data e que passaram por importantes avanços pós-1988, carecem de visibilidade e têem sofrido críticas severas quanto ao não desempenho de seu papel como guardiões-mor dos recursos públi$\cos ^{6}$. Diante disso, cabe indagar: os Tribunais de Contas são capazes de reduzir as irregularidades na execução orçamentária, na celebração de contratos com entidades privadas, na contratação e aposentadoria de pessoal e nos demais atos da Administração Pública? Ademais, após dez anos de vigência da Lei de Responsabilidade Fiscal, é possível estabelecer algum tipo de relação entre essa capacidade institucional dos Tribunais de Contas subnacionais brasileiros e a qualidade das políticas públicas de saúde e educação de seus respectivos Estados? O presente artigo se propõe a investigar esta relação, em busca de evidências empíricas que sinalizem nesta direção.

O controle constitui importante instrumento de governança pública, encarado como mecanismo que possibilita à sociedade acompanhar e fiscalizar os atos públicos, atendendo aos princípios da Administração Pública e da gestão voltada para os cidadãos. Pode, além da essência fiscalizadora, permitir o uso de suas ferramentas para o aprimoramento da gestão e dos serviços públicos7. Ao fornecer suporte à gestão e segurança aos cidadãos quanto aos resultados das políticas públicas, o controle pode aumentar a transparência e a accountability, que são pilares da governança ${ }^{8}$.

A formulação e a implementação de políticas públicas, em qualquer esfera de governo, requer o entendimento da realidade, a identificação das causas críticas e as formulações sobre produtos e resultados que permitam a otimização do uso dos recursos públicos escassos disponíveis. Nesse sentido, a governança está relacionada com a capacidade e as condições internas às instituições, para exercício de suas competências e alcance de seus objetivos. Diz respeito aos recursos técnicos, tecnológicos, de infraestrutura, de pessoal, entre outros de que dispõem as estruturas governamentais para formular, planejar e implantar as políticas públicas, assim como acompanhar, avaliar e fiscalizar a sua execução e resultados obtidos ${ }^{9}$.

Razão pela qual, analisar a capacidade institucional dos Tribunais de Contas subnacionais brasileiros se apresenta como um caminho viável para a compreensão de sua relação com a qualidade das políticas públicas. Para tanto, o argumento desenvolvido no presente artigo é o de que: existe uma relação entre a capacidade institucional dos Tribunais de Contas subnacionais brasileiros e a qualidade das políticas públicas de saúde e educação de seus respectivos Estados.

\footnotetext{
6. SPECK (2000); Idem.

7. FARACO et al. (2016).

8. CAVALCANTE et al. (2012); OLIVEIRA (2015).

9. MPOG (2014).
} 
Nesse sentido, adota-se a abordagem da accountability horizontal, identificandose como objetivo dos Tribunais de Contas dispor de capacidade para realizar ações efetivas de controle da Administração Pública - que vão desde a supervisão de rotina a sanções legais contra ações ou omissões de outros agentes ou agências do Estado, que possam ser qualificadas como delituosas ${ }^{10}$.

Para tanto, operacionaliza-se a capacidade institucional dos Tribunais de Contas subnacionais brasileiros a partir das seguintes variáveis: orçamento, pessoal e contas julgadas irregulares. Não obstante, utiliza-se a análise fatorial para definir os indicadores relativos à qualidade das políticas públicas de saúde e educação de seus respectivos Estados.

É importante destacar que a pesquisa se concentra em instituições de controle externo localizadas dentro de um mesmo país. Metodologicamente, o desenho de pesquisa combina estatística descritiva e multivariada para analisar um banco de dados original elaborado com informações obtidas de diferentes fontes. O período analisado corresponde ao ano de 2010, o qual tem por base a disponibilidade dos dados que serão analisados. Trata-se, também, do ano em que a Lei de Responsabilidade Fiscal completa a sua primeira década de vigência.

Bem se sabe que não basta apenas analisar a atuação dos Tribunais de Contas - de forma isolada - para que se possa avaliar com precisão a sua relação com a qualidade das políticas públicas. Afinal, a fiscalização dos gastos públicos demanda uma ampla rede de controle atuante - e disposta a atuar ${ }^{11}$. De todo modo, o presente trabalho se constitui em esforço para demonstrar que os Tribunais de Contas figuram como importantes instituições de controle, logo, funcionam como checks and balances e, por conseguinte, impactam a qualidade das políticas públicas.

Por fim, estrutura-se o artigo da seguinte forma: a primeira seção resgata o debate sobre controles democráticos e como os Tribunais de Contas subnacionais brasileiros se inserem nesse contexto, sobretudo, com o fim de evidenciar a importância de sua capacidade de fiscalização em relação à qualidade das políticas públicas. A próxima seção se dedica a discutir a metodologia utilizada para responder a questão de pesquisa e testar a hipótese formulada. A seção seguinte traz a lume as análises e os resultados apurados sobre as variáveis propostas. Por fim, a última seção sumariza as considerações finais do artigo.

\section{Os Tribunais de Contas no Contexto dos Controles Democráticos}

O controle se constitui em um ato ou momento político central de um ciclo mais amplo da representação democrática. Essa noção de ciclo completo de representação implica que o momento eleitoral é apenas o começo do processo democrático, que

10. O’DONNELL (1998).

11. Idem. 
deve ter continuidade durante o mandato do governante. De sorte que, para assegurar que os representantes, uma vez a frente de seus cargos públicos, pautem sua conduta pelo melhor interesse de seus representados, é necessário haver instrumentos efetivos e continuados de controle. Por fim, o ciclo da representação se completa quando o povo, a partir dos efeitos gerados pelos atos de controle, é capaz de avaliar se os governantes agiram (ou não) como seus representantes de fato, decidindo-se por sua recondução ou destituição do cargo ${ }^{12}$.

Mas, como os governantes são controlados? A resposta a essa questão nos remete à discussão das diferentes formas de accountability democrática, ou seja, a existência de um aparato institucional que garanta a responsabilização política ininterrupta do poder público diante da sociedade. O controle é, portanto, momento constitutivo do processo mais amplo de accountability ou responsabilização política dos governantes para garantir (ou tentar garantir) que eles atuem, de fato, como representantes do povo. A primeira forma de accountability diz respeito ao processo eleitoral, por meio do qual os eleitores podem recompensar ou punir seus representantes. A segunda forma de accountability passou a ser destacada na literatura justamente pela insatisfação diante dos ínfimos resultados obtidos pelas eleições. Trata-se do conjunto de instituições de controle intraestatal que fornecem os mecanismos de fiscalização contínua dos representantes eleitos - durante o exercício de seus mandatos - e da alta burocracia com responsabilidade decisória. Por fim, a terceira forma de accountability democrática se relaciona à criação de regras estatais intertemporais, pelas quais o poder governamental é limitado em seu escopo de atuação, a fim de se garantir os direitos dos indivíduos e da coletividade que não podem simplesmente ser alterados pelo governo de ocasião ${ }^{13}$.

Essa classificação não diverge daquela construída por O'Donnell ${ }^{14}$, segundo a qual a responsabilidade democrática procura aliar dois mecanismos: de um lado, os relacionados à accountability vertical, na qual os cidadãos controlam de forma direta os governantes, por meio do voto para escolher seus representantes, em plebiscitos sobre matérias substantivas ou ainda pelo controle exercido, por exemplo, em conselhos de usuários de serviços públicos; e, de outro, os vinculados à accountability horizontal, que se efetivam mediante a fiscalização mútua entre os poderes ou por meio de outras agências governamentais que monitoram e fiscalizam o poder público.

12. Ibidem.

13. ABRUCIO y LOUREIRO (2004).

14. Ibidem. 
Quais seriam estas instituições secundárias, capazes de realizar esse controle horizontal? A accountability horizontal é exercida por dois tipos de agências: (1) os Poderes clássicos - Executivo, Legislativo e Judiciário - representando o mecanismo de freios e contrapesos (checks and balances); e (2) agências designadas para este fim, a exemplo das ouvidorias e das Entidades Fiscalizadoras Superiores ${ }^{15}$, tais como: as controladorias, auditorias, tribunais de contas, e similares ${ }^{16}$. Estas últimas atuam no controle administrativo e financeiro dos recursos públicos. Para tanto, qual o desenho institucional destes mecanismos de controle desenvolvido pelo sistema político no plano internacional?

Não há um modelo institucional ideal de instituição secundária de controle que possa ser discutido como parâmetro universal, uma vez que há uma variabilidade nos desenhos institucionais que têm sido adotados com êxito em contextos e tradições históricas distintas. Pode-se identificar, no entanto, três modelos de atuação de instituições de controle no plano internacional que correspondem a três tipos distintos de desenho institucional ${ }^{17}$.

Segundo Rick Stapenhurst e Jack Titsworth ${ }^{18}$, os órgãos de controle se dividem nos seguintes sistemas: Napoleônico, Westminster e Board System. No sistema Napoleônico, aplicado aos países da América Latina e Europa Continental, os órgãos de controle têm autoridade judiciária e administrativa, além de serem autônomos ao legislativo. São chamados também de cour des comptes, termo francês que significa Cortes de Contas, ou ainda, de Tribunais de Contas. No caso do julgamento de contas de chefes do Executivo, tal atribuição fica a cargo do Legislativo, sendo que as contas individuais dos gestores ainda ficam sob a responsabilidade destes Tribunais ${ }^{19}$.

No sistema Westminster - também conhecido como modelo de Auditor Geral encontrado, sobretudo, nos países de origem anglo-saxã, o Auditor-geral é um corpo independente que se reporta ao parlamento e não tem atribuições judiciais, mas pode exercer certos tipos de ações legais, tais como "a liberdade ampla de recrutar pessoal para o serviço e de organizar os trabalhos de auditoria como bem lhe aprouver" ${ }^{20}$. A articulação com o Parlamento se dá através das Comissões de Contas Públicas, ou Public Accounts Comites ${ }^{21}$. A despeito da autonomia que lhe é concedida, o auditor é, em muitos casos, estatutariamente funcionário do Legislativo ${ }^{22}$.

15. Denominação atribuída pela Organização Internacional de Entidades Fiscalizadoras Superiores (INTOSAI, em inglês) aos órgãos encarregados do controle externo das contas públicas.

16. Ibidem.

17. MELO (2008).

18. STAPENHURST y TITSWORTH (2001).

19. CRUZ JUNIOR (2015).

20. Idem, p. 07.

21. STAPENHURST (2004).

22. Ibidem. 
Já o Board System (encontrado em países asiáticos e outros dispersos, como Alemanha, Argentina e Países Baixos), ou Conselho de Contas, se assemelha ao Westminster, mas se diferencia por ter em sua composição um colegiado de auditores, ao invés da figura do Auditor Geral. Tal colegiado pode ser nomeado pelo Presidente ou indicado por ele e aprovado pelo Legislativo. Ainda variam muito os focos e os tipos de auditoria, não possuindo assim um padrão identificável desse sistema.

Dentre os três modelos apresentados acima, o de Tribunal de Contas é o adotado pelo sistema político brasileiro para fazer frente ao desafio de controlar suas contas públicas, os quais surgem no país durante a transição da Monarquia para a República, período em que as instituições estatais se ampliam e se reformulam para se adequarem ao novo regime político.

Organizacionalmente, os tribunais seguiram parcialmente o modelo federativo. O Tribunal de Contas da União (TCU) fiscaliza os recursos da União, incluindo os repasses a Estados, Municípios e Entidades não governamentais. Por sua vez, o Tribunal de Contas do Distrito Federal (TCDF) é responsável pela fiscalização dos recursos distritais e os Tribunais de Contas estaduais (TCEs) são responsáveis pela fiscalização dos recursos estaduais e municipais. Além disso, Cearáe ${ }^{23}$, Bahia, Pará e Goiás criaram, no âmbito estadual, Tribunais de Contas dos municípios (TCMs). Não obstante, Rio de Janeiro e São Paulo possuem Tribunais de Contas municipais autônomos, escolhidos e financiados com recursos municipais ${ }^{24}$.

Vale dizer que, em relação aos Tribunais de Contas subnacionais (TCDF, TCEs e TCMs), estes reproduzem o modelo do TCU tanto em atribuições como em organização interna com algumas pequenas adequações. A organização, o funcionamento e as atribuições dos Tribunais de Contas são estabelecidos pela respectiva legislação distrital, estadual e municipal. Além disso, cada tribunal dispõe de sua própria lei orgânica ou regulamento interno específico. Outra adequação em relação ao modelo do TCU é quanto ao número de membros do seu Colegiado Superior: o colegiado do TCU é composto por o9 (nove) membros - denominados Ministros, ao passo que o colegiado dos Tribunais de Contas subnacionais é formado por 07 (sete) membros denominados Conselheiros, ressalvando-se apenas o colegiado do Tribunal de Contas do Município de São Paulo, que é composto por 05 (cinco) membros ${ }^{25}$.

Ao longo da história republicana brasileira, as atribuições constitucionais dos Tribunais de Contas se ampliaram. Sendo que o ápice dessas transformações veio com a promulgação da Constituição de 1988. Entre elas, cabe citar: a ampliação das funções das Cortes de Contas, abrangendo também o controle de desempenho; a indicação da maioria de seus dirigentes pelo Poder Legislativo e a atribuição à população de poder de denúncia de irregularidades.

23. O TCM-CE foi extinto em 2017, por meio da Emenda Constitucional no 92, de 21/08/2017.

24. SPECK (2013).

25. MORAES (2006). 
No que tange às suas funções, destacam-se a definição e a ampliação de suas competências exclusivas como os maiores ganhos para estes órgãos dentro da estrutura de poder. Além da prerrogativa de elaborar parecer técnico sobre a tomada de contas do Executivo, eles também assumiram a função de realizar auditorias de desempenho das políticas públicas, superando assim a atividade de cunho estritamente legalista, que sempre os caracterizou. Isso significa verificar não apenas se o gasto foi realizado segundo as normas legais, mas também se ele produziu o resultado esperado. Inclui-se, ainda, no rol das atribuições, a apreciação da legalidade dos contratos, da admissão de pessoal, concessão de aposentadorias, reformas e pensões, além de se manifestar acerca da legalidade das licitações em caráter prévio, evitando, assim, benefícios a determinados grupos econômicos ${ }^{26}$.

O Quadro 1 sintetiza as principais competências constitucionais dos Tribunais de Contas:

Quadro 1. Competências Constitucionais dos Tribunais de Contas

\begin{tabular}{|l|}
\hline \multicolumn{1}{|c|}{ ROL DE COMPETÊNCIAS } \\
\hline 1. Emitir parecer sobre as contas anuais prestadas pelo chefe do Poder Executivo. \\
\hline 2. Julgar as contas dos responsáveis por recursos públicos. \\
\hline 3. Apreciar a legalidade de atos relacionados à admissão e à aposentadoria de pessoal. \\
\hline $\begin{array}{l}\text { 4. Fiscalizar o uso dos recursos públicos, por meio de auditorias e inspeções de iniciativa } \\
\text { própria ou do Legislativo. }\end{array}$ \\
\hline $\begin{array}{l}\text { 5. Aplicar sanções e determinar a correção de ilegalidades e irregularidades em atos e } \\
\text { contratos. }\end{array}$ \\
\hline $\begin{array}{l}\text { 6. Apurar representações e denúncias apresentadas por qualquer cidadão, partido político, } \\
\text { associação ou sindicato sobre irregularidades ou ilegalidades na aplicação dos recursos } \\
\text { públicos. }\end{array}$ \\
\hline
\end{tabular}

Fonte: Elaboração própria, a partir de Constituição Federal (1988).

Não obstante, o Quadro 2 abaixo traça as principais características dos Tribunais de Contas no Brasil: 


\section{Quadro 2. Principais Características dos Tribunais de Contas no Brasil}

\begin{tabular}{|c|c|}
\hline FUNÇÕES & $\begin{array}{l}\text { As funções básicas dos Tribunais de Contas podem ser agrupadas em oito } \\
\text { grandes categorias: fiscalizadora (auditam/fiscalizam, apreciam atos), ju- } \\
\text { dicante (julgam contas), sancionadora (aplicam sanções/penalidades), } \\
\text { consultiva (respondem consultas/emitem parecer prévio), informativa } \\
\text { (prestam informações ao Legislativo e ao Ministério Público), corretiva } \\
\text { (determinam, fixam prazos, sustam atos), normativa (expedem normativos, } \\
\text { fixam coeficientes) e de ouvidoria (examinam denúncias e representações). }\end{array}$ \\
\hline $\begin{array}{l}\text { PROCEDIMENTOS } \\
\text { O P E R A C I O N A I S } \\
\text { BÁSICOS DE FISCAL- } \\
\text { IZAÇÃO }\end{array}$ & $\begin{array}{l}\text { Para desempenhar suas atribuições, os Tribunais empregam quatro pro- } \\
\text { cedimentos básicos: tomadas e prestações de contas, tomadas de contas } \\
\text { especiais, fiscalizações e monitoramentos. }\end{array}$ \\
\hline $\begin{array}{l}\text { FOCO DE CON- } \\
\text { TROLE }\end{array}$ & $\begin{array}{l}\text { O foco da auditoria de conformidade se concentra em examinar a legali- } \\
\text { dade e a legitimidade dos atos de gestão dos responsáveis sujeitos a sua } \\
\text { jurisdição, quanto ao aspecto contábil, financeiro, orçamentário e patrimo- } \\
\text { nial. Ao passo que o foco da auditoria de natureza operacional se destina a } \\
\text { avaliar o desempenho dos órgãos e entidades jurisdicionados, assim como } \\
\text { dos sistemas, programas, projetos e atividades governamentais, quanto aos } \\
\text { aspectos da economicidade, eficiência e eficácia dos atos praticados. }\end{array}$ \\
\hline $\begin{array}{l}\text { SUJEITOS PASSIVOS } \\
\text { DO CONTROLE }\end{array}$ & $\begin{array}{l}\text { Nos termos da Constituição, encontram-se sob jurisdição dos Tribunais - } \\
\text { e, portanto, figuram como sujeitos passivos do controle - qualquer pessoa } \\
\text { física ou jurídica, pública ou privada, que utilize, arrecade, guarde, gerencie, } \\
\text { aplique ou administre dinheiros, bens e valores públicos. }\end{array}$ \\
\hline $\begin{array}{ll}\text { VINCULAÇÃO } & \text { IN- } \\
\text { STITUCIONAL } & \end{array}$ & $\begin{array}{l}\text { O entendimento majoritário é no sentido de que os Tribunais de Contas são } \\
\text { órgãos de extração constitucional, independentes e autônomos, que auxil- } \\
\text { iam o Poder Legislativo no exercício do controle externo. }\end{array}$ \\
\hline $\begin{array}{l}\text { NATUREZA JU- } \\
\text { RÍDICA DA INSTI- } \\
\text { TUIÇÃO }\end{array}$ & $\begin{array}{l}\text { A maior parte da doutrina e a jurisprudência quase unânime dos tribunais } \\
\text { superiores, inclusive do próprio Supremo Tribunal Federal, têm reconhe- } \\
\text { cido os Tribunais de Contas como uma Corte administrativa, autônoma, } \\
\text { com competência para julgar contas dos administradores e responsáveis } \\
\text { por bens e valores públicos, e dotada de jurisdição própria, peculiar e es- } \\
\text { pecífica, distinta da jurisdição em sentido estrito. }\end{array}$ \\
\hline $\begin{array}{l}\text { NATUREZA JURÍDI- } \\
\text { CA DAS DECISÕES }\end{array}$ & $\begin{array}{l}\text { Para a maior parte dos estudiosos e dos juristas, as deliberações das Cortes } \\
\text { de Contas consistem em juízos acerca da exatidão de contas e de atos sub- } \\
\text { metidos a seu exame. Elas fazem coisa julgada administrativa, o que impede } \\
\text { sua revisão e torna seu cumprimento obrigatório nessa esfera, e não po- } \\
\text { dem ser questionadas senão por mandado de segurança junto aos Tribunais } \\
\text { Superiores. Além disso, a jurisprudência do Supremo Tribunal Federal e a } \\
\text { doutrina majoritária, ao reconhecerem os Tribunais de Contas como juiz } \\
\text { natural das matérias inseridas em sua competência, têm entendido que suas } \\
\text { deliberações restringem parcialmente a atuação do Judiciário, que somente } \\
\text { pode examinar erros de procedimento, sem possibilidade de manifestação } \\
\text { sobre eventual erro de julgamento. }\end{array}$ \\
\hline
\end{tabular}

Fonte: Elaboração própria, a partir de Ferreira (2013). 
Sano y Montenegro Filho ${ }^{27}$ afirmam que as Entidades de Fiscalização Superior, como os Tribunais de Contas, estão a ser cada vez mais demandadas para realizar trabalhos qualitativos, abrangendo os critérios de eficiência, eficácia e efetividade em suas ações de controle. No mesmo sentido, Ferreira ${ }^{28}$ - ao analisar o papel do Tribunal de Contas da União como órgão de avaliação de políticas públicas - afirma que a apreciação das contas anualmente prestadas pelo Presidente da República, por exemplo, exige do Tribunal um extraordinário trabalho de avaliação de políticas públicas, sendo talvez a competência onde mais amplamente o Tribunal esmiúça as atividades governamentais. Ademais, no exercício de sua missão fiscalizadora, o Tribunal observa não apenas o aspecto da legalidade, mas também o da legitimidade e economicidade, o que alarga em muito a possibilidade de conduzir avaliações de amplo alcance, especialmente no caso das fiscalizações de natureza operacional.

Levando-se em conta que estas atividades de controle possuem um custo financeiro considerável (remuneração e qualificação de servidores, manutenção de estrutura adequada, auditorias in loco, manutenção de sistemas, entre diversas outras questões), espera-se que o fortalecimento da capacidade institucional dos Tribunais de Contas - a partir de investimentos em sua estrutura - é determinante para o seu ativismo, contribuindo positivamente com a qualidade das políticas públicas. Para tanto, considera-se o argumento de Fukuyama ${ }^{29}$, segundo o qual, instituições que dispõem de recursos suficientes para o desempenho de suas atividades funcionam melhor em todos os níveis.

Mas analisar a relação entre a capacidade institucional dos Tribunais de Contas e a qualidade das políticas públicas não se constitui em uma tarefa fácil. Muito embora o sistema Napoleônico de controle não seja restrito apenas ao Brasil - visto que o modelo de Tribunais de Contas se aplica a vários países da América Latina e Europa Continental $^{30}$, pouco se sabe sobre seu desempenho e efetividade ${ }^{31}$.

Ademais, embora se tratem de instituições de longa data e que passaram por importantes avanços pós-1988, carecem de visibilidade e tem sofrido críticas severas quanto ao não desempenho de seu papel como guardiões-mor dos recursos públicos, sobretudo, porque têm convivido com práticas tradicionais de nepotismo e corrupção ${ }^{32}$. Diante disso, cabe indagar: os Tribunais de Contas são capazes de exercer suas funções de modo efetivo e, por via de consequência, vindo a contribuir com qualidade das políticas públicas?

27. SANO Y MONTENEGRO FILHO (2013).

28. FERREIRA (2012).

29. FUKUYAMA (2005).

30. Idem; Idem.

31. Ibidem; FIGUEIREDO (2007); TEIXEIRA y ALVES (2011).

32. Op. cit.; Ibidem; Op. cit. 
Speck ${ }^{33}$ afirma que as sugestões para medir o desempenho dos Tribunais de Contas estão relacionadas ao cálculo da economia resultante de suas atividades, englobando três possibilidades, quais sejam: os ganhos por antecipação, por economia imediata ou a longo prazo. Contudo, segundo o autor, essa forma de avaliação dos resultados dos Tribunais de Contas é questionável. Porque ela é, ao mesmo tempo, estreita e ampla demais. Estreita porque não leva em conta os ganhos que vão além do caso individual corrigido, ao eliminar-se erros sistêmicos. Ademais, a economia alcançada com o cancelamento de um contrato sem licitação em andamento somente poderá ser calculada em termos monetários, caso as ofertas realizadas nessas condições possam ser comparadas com ofertas reais, por ocasião da licitação. Não obstante, outro caso complicado é a economia conseguida com a correção de um regulamento de contratação, que potencialmente atinja todos os contratos a serem estimados no futuro. Esses efeitos a longo prazo são praticamente impossíveis de serem estimados em termos econômicos.

Nesse sentido, trabalhos sobre capacidade institucional trazem grandes contribuições e insights importantes para pensar a efetividade dos Tribunais de Contas. Afinal, análises sobre o fortalecimento da capacidade institucional do Estado a evidenciam como uma condição necessária para a adequada implementação de mecanismos de governança pública, com vistas a sua maior efetividade.

Tanto que a partir da promulgação da Lei de Responsabilidade Fiscal (LRF), o Governo Federal percebeu que precisaria montar uma estrutura para fiscalizar o cumprimento desse novo marco regulatório. Chegou-se até a discutir sobre a contratação de auditorias independentes, mas, questionou-se o porquê de gastar dinheiro com empresas privadas se já existiam estruturas públicas específicas para o controle das contas públicas governamentais. A partir de então, o Governo Federal passou a considerar os Tribunais de Contas subnacionais como uma peça imprescindível para o sucesso da LRF, confiando a esses órgãos a responsabilidade de garantir a fiel observância de todos os impositivos da Lei pelos gestores públicos ${ }^{34}$.

Todavia, observou-se que a capacidade institucional dos Tribunais de Contas precisaria ser reforçada em diversos aspectos: primeiro tecnologicamente, criando sistemas informatizados para recebimento de informações por parte dos estados e municípios. Segundo, em termos de capacitação dos funcionários que precisariam de treinamento para saber lidar com esse novo marco regulatório. E terceiro, em termos de integração técnica e política, pois era necessária uma padronização dos procedimentos e conceitos aplicados para que a Lei fosse implementada de forma uniforme. Foi a partir desse quadro de grandes deficiências na estrutura dos Tribunais de Contas subnacionais brasileiros que surgiu o Programa de Modernização do Sistema de Controle Externo dos Estados e Municípios Brasileiros - PROMOEX ${ }^{35}$.

\section{Ibidem.}

34. Idem.

35. Ibidem. 
O principal escopo do programa consistia em "fortalecer o sistema de controle externo como instrumento da cidadania, incluindo a intensificação das relações intergovernamentais e interinstitucionais, com vistas ao cumprimento da Lei de Responsabilidade Fiscal". Para tanto, em 14 de setembro de 2005 foi assinado o Contrato de Empréstimo $n^{\circ}$ 1628/OC-BR entre o Governo Federal e o Banco Interamericano de Desenvolvimento - BID para apoiar o referido Programa ${ }^{36}$. Este contrato teve a sua execução finalizada em 14 de setembro de 2013. Dentro dos US\$ 64,4 milhões previstos em contrato, $78,88 \%$ foram utilizados, ou seja, US\$ 50,8 milhões - sendo US\$ 27,5 milhões da fonte BID (equivalente a $71,24 \%$ do montante contratado junto ao banco - US\$ 38,6 milhões) e mais US\$ 23,3 milhões em contrapartida (equivalente a 90,31\% do ofertado - US\$ 25,8 milhões) ${ }^{37}$.

Assim, é possível concluir que, de fato, o fortalecimento da capacidade institucional dos Tribunais de Contas subnacionais brasileiros é uma condição necessária para sua maior efetividade. Entretanto, como os trabalhos específicos sobre essas instituições de controle vêm incorporando essas discussões?

Melo et al..$^{38}$ buscam explicar o desempenho dos Tribunais de Contas estaduais brasileiros pela rotatividade das elites políticas que controlam os governos estaduais; pela volatilidade eleitoral dos eleitores; e por seus arranjos institucionais internos (incluindo, entre outros, as regras para o recrutamento dos conselheiros). Para tanto, quatro classes de exercícios econométricos são aplicadas pelos autores: duas para estimar os determinantes do ativismo institucional de um Tribunal de Contas (ativismo geral e auto-iniciativa); uma para estimar os determinantes da escolha do governador ao nomear um conselheiro; e, finalmente, um teste para avaliar os determinantes da "propensão a rejeitar ou aprovar" um relatório de contas submetido por governadores, prefeitos ou legislaturas. As variáveis utilizadas são: (1) o número de auditorias realizadas pelo tribunal; (2) o número de unidades administrativas sob jurisdição; (3) o orçamento executado pelo tribunal em 2004; (4) o total de equipamentos; (5) o total de funcionários; (6) a idade do tribunal; (7) a presença de conselheiros oriundos das carreiras de auditor ou procurador de contas; (8) a presença do Ministério Público junto ao Tribunal de Contas (9) a volatilidade eleitoral no Estado; e (10) a rotatividade do governo estadual.

Os principais resultados apontados pela pesquisa são: (a) a rotatividade do governo estadual e a presença de conselheiros oriundos das carreiras de auditor ou procurador de contas melhoram o desempenho dos Tribunais de Contas subnacionais; (b) quanto maior a capacidade institucional do tribunal, mais ativo ele tende a ser; (c) a

36. MPOG (2015).

37. MPOG (2013).

38. Idem. 
presença do Ministério Público junto ao Tribunal de Contas é crucial para sancionar os maus comportamentos dos políticos; e, por fim, (d) há uma correlação inversa entre os recursos disponíveis para os tribunais e sua propensão a infligir sanções aos políticos eleitos ${ }^{39}$.

É possível notar que o trabalho de Melo et $a l .{ }^{40}$ se concentra em avaliar o desempenho dos Tribunais de Contas estaduais sem, contudo, analisar o efeito desta performance sobre o contexto em que se inserem. Restando prejudicada, portanto, a análise de sua relação com a qualidade das políticas públicas. Com efeito, Rocha et al ${ }^{41}$ oferecem uma importante contribuição nessa direção. Objetivando analisar a relação entre a capacidade institucional dos 27 Tribunais de Contas Estaduais brasileiros e a corrupção, eles combinam estatística descritiva e multivariada para analisar um banco de dados elaborado a partir de Melo et al. ${ }^{42}$ e Ferraz y Finan ${ }^{43}$. Em particular, os autores utilizam análise de componentes principais para estimar um indicador de capacidade institucional, a partir das seguintes variáveis: (1) o percentual do orçamento estadual, (2) a transparência orçamentária e (3) a antiguidade de cada tribunal. Empregam também um modelo linear de mínimos quadrados ordinários para estimar o efeito da capacidade institucional sobre incidência de corrupção - corrupção tratada por eles como os casos de improbidade administrativa ${ }^{44}$ detectados nos respectivos Estados.

\section{Ibidem.}

40. Op. cit.

41. Idem.

42. Op. cit.

43. FERRAZ y FINAN (2010); para detalhes da metodologia, conferir Rocha et al. (2014).

44. De acordo com Rocha et al. (2014), a previsão legal dos atos de improbidade administrativa foi consubstanciada pela Lei n 8.429/1992, que dispõe sobre as sanções aplicáveis aos agentes públicos nos casos de enriquecimento ilícito no exercício de mandato, cargo, emprego ou função na administração pública direta, indireta ou fundacional e dá outras providências. Sendo que o Art. $9^{\circ}$ estabelece que: constitui ato de improbidade administrativa importando enriquecimento ilícito auferir qualquer tipo de vantagem patrimonial indevida em razão do exercício de cargo, mandato, função, emprego ou atividade nas entidades mencionadas no art. $1^{\circ}$ da Lei no 8.429/1992; o Art. 10 estabelece que: constitui ato de improbidade administrativa que causa lesão ao erário qualquer ação ou omissão, dolosa ou culposa, que enseje perda patrimonial, desvio, apropriação, malbaratamento ou dilapidação dos bens ou haveres das entidades referidas no art. $1^{\circ}$ da Lei $n^{\circ}$ 8.429/1992; o Art. 10-A determina que: constitui ato de improbidade administrativa qualquer ação ou omissão para conceder, aplicar ou manter benefício financeiro ou tributário contrário ao que dispõem o caput e o $\$ 1^{\circ}$ do art. $8^{\circ}$-A da Lei Complementar $n^{\circ} 116$, de 31 de julho de 2003; e o Art. 11 assevera que: constitui ato de improbidade administrativa que atenta contra os princípios da administração pública qualquer ação ou omissão que viole os deveres de honestidade, imparcialidade, legalidade, e lealdade às instituições. 
De acordo com o referido desenho de pesquisa, os autores constatam que: (a) comparativamente, o Estado de São Paulo apresenta o Tribunal com maior capacidade institucional, enquanto o Estado de Mato Grosso do Sul apresenta o pior desempenho; (b) em média, quanto maior o orçamento do tribunal, menor é o seu nível de transparência e (c) quanto maior a capacidade institucional do tribunal, maior é a probabilidade de detectar casos de improbidade administrativa.

O trabalho de Rocha et al..$^{45}$, a exemplo do trabalho de Melo et al.$^{46}$, reafirma a relevância da capacidade institucional dos Tribunais de Contas para a efetividade de sua atuação. E é nesse contexto em que se insere esta pesquisa. Partindo-se da premissa de que a capacidade institucional de uma organização está associada à sua aptidão de viabilizar o cumprimento de suas competências, objetivos e metas ${ }^{47}$, este trabalho se propõe a analisar a relação entre a capacidade institucional dos Tribunais de Contas subnacionais brasileiros e a qualidade das políticas de saúde e educação de seus respectivos Estados.

Para a consecução deste objetivo, as variáveis eleitas para medir a capacidade institucional dos Tribunais de Contas são: orçamento, pessoal e contas julgadas irregulares. O orçamento e o quantitativo de pessoal dos Tribunais de Contas subnacionais afeta positivamente a sua capacidade institucional ${ }^{48}$. Ao passo que as contas julgadas irregulares pelos Tribunais de Contas subnacionais possuem o condão de gerar um impacto direto na boa gestão dos recursos e das políticas públicas. Na medida em que tais julgamentos além de coibirem o mau uso do dinheiro público, podem vir a configurar ato doloso de improbidade administrativa que, por sua vez, podem gerar responsabilização na esfera judicial por meio da ação civil de improbidade administrativa $^{49}$. Os referidos dados se encontram disponíveis na Tabela 1 abaixo:

45. Ibidem.

46. Op. cit.

47. FERNANDES (2016).

48. Op. cit.; Op. cit.

49. Op. cit. 
Tabela 1. Variáveis Selecionadas para o Cálculo da Capacidade Institucional dos Tribunais de Contas Subnacionais Brasileiros.

\begin{tabular}{|c|c|c|c|}
\hline TRIBUNAL & ORÇAMENTO (2010) & PESSOAL (2010) & $\begin{array}{l}\text { CONTAS JULGADAS } \\
\text { IRREGULARES (2010) }\end{array}$ \\
\hline TCE-AC & $\mathrm{R} \$ 29.649 .000,00$ & 153 & 33 \\
\hline TCE-AL & $\mathrm{R} \$ 56.744 .000,00$ & 731 & 03 \\
\hline TCE-AM & $\mathrm{R} \$ 91.390 .000,00$ & NA & 37 \\
\hline TCE-AP & $\mathrm{R} \$ 78.026 .000,00$ & 85 & 17 \\
\hline TCE-BA & $\mathrm{R} \$ 127.247 .000,00$ & NA & 15 \\
\hline TCM-BA & $\mathrm{R} \$ 100.433 .000,00$ & NA & 39 \\
\hline TCE-CE & $\mathrm{R} \$ 27.025 .000,00$ & NA & NA \\
\hline TCM-CE & $\mathrm{R} \$ 41.207 .000,00$ & NA & NA \\
\hline TC-DF & R\$ 194.994.000,00 & 528 & 29 \\
\hline TCE-ES & $\mathrm{R} \$ 82.591 .000,00$ & 493 & 40 \\
\hline TCE-GO & $\mathrm{R} \$ 165.471 .000,00$ & NA & 01 \\
\hline TCM-GO & $\mathrm{R} \$ 71.968 .000,00$ & 385 & 12 \\
\hline TCE-MA & $\mathrm{R} \$ 60.106 .000,00$ & NA & NA \\
\hline TCE-MG & $\mathrm{R} \$ 295.557 .000,00$ & 1321 & 89 \\
\hline TCE-MS & $\mathrm{R} \$ 108.760 .000,00$ & 499 & 9 \\
\hline TCE-MT & $\mathrm{R} \$ 125.464 .000,00$ & 575 & 45 \\
\hline TCE-PA & $\mathrm{R} \$ 81.951 .000,00$ & 303 & 9 \\
\hline TCM-PA & $\mathrm{R} \$ 75.924 .000,00$ & NA & NA \\
\hline TCE-PB & $\mathrm{R} \$ 82.323 .000,00$ & 445 & 08 \\
\hline TCE-PE & $\mathrm{R} \$ 202.276 .000,00$ & 775 & 85 \\
\hline TCE-PI & $\mathrm{R} \$ 47.827 .000,00$ & 396 & 129 \\
\hline TCE-PR & $\mathrm{R} \$ 177.392 .000,00$ & 668 & 11 \\
\hline TCE-RJ & $\mathrm{R} \$ 423.515 .000,00$ & 1438 & 16 \\
\hline TCM-RJ & $\mathrm{R} \$ 117.662 .000,00$ & 536 & 15 \\
\hline TCE-RN & $\mathrm{R} \$ 37.395 .000,00$ & 232 & 08 \\
\hline TCE-RO & $\mathrm{R} \$ 65.607 .000,00$ & 389 & 04 \\
\hline TCE-RR & $\mathrm{R} \$ 37.295 .000,00$ & 257 & 04 \\
\hline TCE-RS & $\mathrm{R} \$ 254.694 .000,00$ & 822 & 52 \\
\hline TCE-SC & $\mathrm{R} \$ 114.416 .000,00$ & 509 & 02 \\
\hline TCE-SE & $\mathrm{R} \$ 87.685 .000,00$ & NA & $\mathrm{NA}$ \\
\hline TCE-SP & $\mathrm{R} \$ 455.187 .000,00$ & 2141 & 09 \\
\hline TCM-SP & $\mathrm{R} \$ 178.934 .000,00$ & 443 & 16 \\
\hline TCE-TO & $\mathrm{R} \$ 59.935 .000,00$ & 478 & 10 \\
\hline
\end{tabular}

Obs. 1: Pessoal = Total de Conselheiros + Total de Conselheiros Substitutos + Total de Servidores Concursados + Total de Servidores Comissionados, cujos dados foram obtidos a partir de Tribunais de Contas subnacionais (via Lei de Acesso à Informação).

Obs. 2: NA = Not Available (Não Disponível).

Fonte: Elaboração própria, a partir da Lei Orçamentária Anual - LOA de cada um dos respectivos Estados / Tribunais de Contas Subnacionais (via Lei de Acesso à Informação) / Secretaria do Tesouro Nacional (STN) / Instituto Brasileiro de Geografia e Estatística (IBGE) / Tribunais Regionais 
Para a escolha das variáveis de qualidade das políticas públicas de saúde e educação de seus respectivos Estados, adotam-se os critérios de que se valeram Lopes y Toyoshima ${ }^{50}$, segundo os quais a Análise Fatorial (AF) orienta a escolha dos indicadores. É importante destacar que a escolha das políticas públicas de saúde e educação tem por justificativa o fato de que estas duas pastas figuram entre as mais cobiçadas entre os políticos, sobretudo, em função da visibilidade e do volume de recursos que recebem ${ }^{51}$.

A Análise Fatorial ${ }^{52}$ é uma técnica estatística multivariada de redução de dados que objetiva gerar fatores/componentes não observados a partir das variáveis observadas, com base no padrão de correlação verificado entre as variáveis originais ${ }^{53}$. Com efeito, o modelo utilizado neste estudo possui as seguintes características: (1) análise via matriz de correlação; (2) autovalores maiores que um; (3) método de extração de Fatoração pelo Eixo Principal; (4) rotação ortogonal Varimax com normalização de Kaiser; e (5) casos ausentes substituídos pela média.

Para o emprego da AF, foram selecionados inicialmente 15 indicadores de educação e de saúde, constantes da Tabela 2 abaixo:

Tabela 2. Indicadores Utilizados na Análise Fatorial.

\begin{tabular}{|l|c|}
\hline \multicolumn{1}{|c|}{ INDICADOR } & ANO \\
\hline Taxa de analfabetismo - 11 a 14 anos & 2010 \\
\hline Taxa de analfabetismo - 15 anos ou mais & 2010 \\
\hline Taxa de analfabetismo - 18 a 24 anos & 2010 \\
\hline$\%$ de crianças de 0 a 5 anos na escola & 2010 \\
\hline \% de crianças de 5 a 6 anos na escola & 2010 \\
\hline$\%$ de crianças de 6 a 14 anos na escola & 2010 \\
\hline$\%$ de adolescentes de 15 a 17 anos na escola & 2010 \\
\hline \% de jovens de 18 a 24 anos na escola & 2010 \\
\hline$\%$ de adolescentes de 15 a 17 anos com fundamental completo & 2010 \\
\hline$\%$ de jovens de 18 a 20 anos com médio completo & 2010 \\
\hline Esperança de vida ao nascer & 2010 \\
\hline Probabilidade de sobrevivência até 60 anos & 2010 \\
\hline \% da população em domićlios com banheiro e água encanada & 2010 \\
\hline$\%$ da população em domicílios com coleta de lixo & 2010 \\
\hline \% da população em domićlios com energia elétrica & 2010 \\
\hline
\end{tabular}

Fonte: Elaboração própria, a partir de Atlas do Desenvolvimento Humano no Brasil (2010).

50. LOPES y TOYOSHIMA (2013); para detalhes da metodologia, conferir Lopes y Toyoshima (2013).

51. PASSARINHO (2018).

52. Para detalhes sobre a análise fatorial, conferir Figueiredo Filho et al. (2014).

53. FIGUEIREDO FILHO et al. (2014). 
De sorte que, após a aplicação da Análise Fatorial, foram selecionados os quatro indicadores de maior peso pertencentes ao primeiro fator, conforme Tabela 3 abaixo: Tabela 3. Cargas Fatoriais das Variáveis Utilizadas no Modelo.

\begin{tabular}{|l|c|c|c|}
\hline \multirow{2}{*}{ INDICADOR } & \multicolumn{3}{c|}{ Cargas Fatoriais } \\
\cline { 2 - 4 } & $\mathbf{1}$ & $\mathbf{2}$ & $\mathbf{3}$ \\
\hline Taxa de analfabetismo - 11 a 14 anos & $-0,943$ & 0,211 & 0,030 \\
\hline Taxa de analfabetismo - 15 anos ou mais & $-0,807$ & 0,494 & $-0,148$ \\
\hline Taxa de analfabetismo - 18 a 24 anos & $-0,892$ & 0,347 & $-0,056$ \\
\hline \% de crianças de 0 a 5 anos na escola & 0,315 & 0,778 & $-0,034$ \\
\hline \% de crianças de 5 a 6 anos na escola & 0,147 & 0,941 & 0,061 \\
\hline \% de crianças de 6 a 14 anos na escola & 0,564 & 0,646 & $-0,055$ \\
\hline \% de adolescentes de 15 a 17 anos na escola & 0,267 & 0,422 & 0,680 \\
\hline \% de jovens de 18 a 24 anos na escola & $-0,251$ & 0,008 & 0,872 \\
\hline \% de adolescentes de 15 a 17 anos com fundamental completo & 0,857 & $-0,158$ & $-0,084$ \\
\hline \% de jovens de 18 a 20 anos com médio completo & 0,932 & $-0,074$ & 0,049 \\
\hline Esperança de vida ao nascer & 0,919 & $-0,225$ & 0,178 \\
\hline Probabilidade de sobrevivência até 60 anos & $-0,223$ & $-0,308$ & 0,284 \\
\hline \% da população em domicílios com banheiro e água encanada & 0,907 & 0,202 & $-0,045$ \\
\hline \% da população em domicílios com coleta de lixo & 0,660 & $-0,145$ & 0,004 \\
\hline \% da população em domićlios com energia elétrica & 0,649 & 0,468 & $-0,161$ \\
\hline
\end{tabular}

Fonte: Elaboração própria, a partir de Atlas do Desenvolvimento Humano no Brasil (2010).

Em termos práticos, estes indicadores têm o maior poder de explicação da estrutura total de variância dos dados. Assim, os quatro indicadores eleitos para figurarem como indicadores de qualidade das políticas de educação e saúde são: (a) o percetual de jovens de 18 a 20 anos com ensino médio completo; (b) a taxa de analfabetismo na faixa etária de 11 a 14 anos; (c) a esperança de vida ao nascer; e (d) o percentual de pessoas que vivem em domicílios com banheiro e água encanada.

Os dois primeiros indicadores - "a" e "b" - podem ser entendidos como medidas de qualidade do ensino nos Estados. O indicador "a" mede a razão entre a população de 18 a 20 anos de idade que já concluiu o ensino médio em quaisquer de suas modalidades (regular seriado, não seriado, educação de jovens e adultos ou supletivo) e o total de pessoas nesta faixa etária multiplicado por 10o. Ao passo que o indicador "b" calcula a razão entre a população de 11 a 14 anos de idade que não sabe ler nem escrever um bilhete simples e o total de pessoas nesta faixa etária, multiplicada por 100.

Os dois últimos indicadores - "c" e "d", por sua vez, podem ser entendidos como medidas de boas condições de saúde nos Estados. O indicador "c" trata do número médio de anos que as pessoas deverão viver a partir do nascimento, se permanecerem constantes ao longo da vida o nível e o padrão de mortalidade por idade, prevalecen- 
tes no ano do Censo. Enquanto o indicador "d" calcula a razão entre a população que vive em domicílios particulares permanentes com água encanada em, pelo menos, um de seus cômodos e com banheiro exclusivo e a população total residente em domicílios particulares permanentes, multiplicada por 100. Os referidos dados se encontram disponíveis no Quadro 3 abaixo:

Quadro 3. Indicadores de Qualidade das Políticas de Educação e Saúde Selecionados.

\begin{tabular}{|c|c|c|c|c|}
\hline UF & $\begin{array}{l}\text { Percentual de jovens de } 18 \\
\text { a } 20 \text { anos com ensino mé- } \\
\text { dio completo (2010) }\end{array}$ & $\begin{array}{c}\text { Taxa de analfabetismo } \\
\text { na faixa etária de } 11 \text { a } \\
14(2010)\end{array}$ & $\begin{array}{l}\text { Esperança re de } \\
\text { vida ao nascer } \\
(2010)\end{array}$ & $\begin{array}{l}\text { Percentual de pes- } \\
\text { soas que vivem em } \\
\text { domicílios com } \\
\text { banheiro e água } \\
\text { encanada (2010) }\end{array}$ \\
\hline $\mathrm{AC}$ & 31,98 & 6,64 & 71,63 & 47,42 \\
\hline AL & 25,86 & 8,96 & 70,32 & 75,64 \\
\hline AP & 35,73 & 3,81 & 73,8 & 66,38 \\
\hline AM & 28,76 & 6,54 & 73,3 & 62,16 \\
\hline BA & 29,49 & 5,01 & 71,97 & 77,6 \\
\hline CE & 37,39 & 4,65 & 72,6 & 76,28 \\
\hline DF & 53,48 & 1,1 & 77,35 & 96,01 \\
\hline ES & 44,93 & 1,76 & 75,1 & 96,89 \\
\hline GO & 44,62 & 1,57 & 74,6 & 93,66 \\
\hline MA & 29,6 & 7,59 & 70,4 & 51,79 \\
\hline MT & 42,36 & 2 & 74,25 & 90,37 \\
\hline MS & 40,43 & 1,55 & 74,96 & 93,76 \\
\hline MG & 42,82 & 1,52 & 75,3 & 94,91 \\
\hline PA & 24,1 & 6,32 & 72,36 & 57,5 \\
\hline PB & 32,88 & 5,39 & 72 & 78,91 \\
\hline $\mathrm{PR}$ & 48,05 & 1,14 & 74,8 & 96,69 \\
\hline $\mathrm{PE}$ & 32,64 & 5,66 & 72,32 & 78,22 \\
\hline PI & 29,44 & 6,5 & 71,62 & 67,12 \\
\hline RJ & 42,93 & 1,76 & 75,1 & 94,73 \\
\hline $\mathrm{RN}$ & 36,11 & 6,63 & 72,52 & 85,06 \\
\hline RS & 43,79 & 1,29 & 75,38 & 96,46 \\
\hline RO & 36,47 & 1,59 & 72,97 & 79,62 \\
\hline RR & 40,53 & 5,13 & 73,51 & 74,04 \\
\hline $\mathrm{SC}$ & 51,8 & 1,05 & 76,61 & 97 \\
\hline SP & 52,33 & 1,49 & 75,69 & 97,12 \\
\hline SE & 30,55 & 5,52 & 71,84 & 82,24 \\
\hline TO & 40,73 & 2,9 & 72,56 & 80,41 \\
\hline
\end{tabular}

Fonte: Elaboração própria, a partir de Atlas do Desenvolvimento Humano no Brasil (2010). 
Registre-se que as variáveis em questão são reportadas por unidade da federação a fim de que seja possível relacioná-las aos indicadores dos Tribunais de Contas subnacionais.

\section{Desenho de Pesquisa}

Segundo King ${ }^{54}$, o padrão de replicabilidade requer a disponibilização de informações suficientes que permitam: compreender, avaliar e replicar os resultados de um determinado trabalho sem informação adicional do autor do estudo. Em outras palavras, o componente básico do padrão de replicabilidade é que o pesquisador deixe claro o passo a passo de como os dados foram coletados e analisados. O Quadro 4 abaixo resume as características essenciais deste trabalho, a saber:

Quadro 4. Desenho de Pesquisa

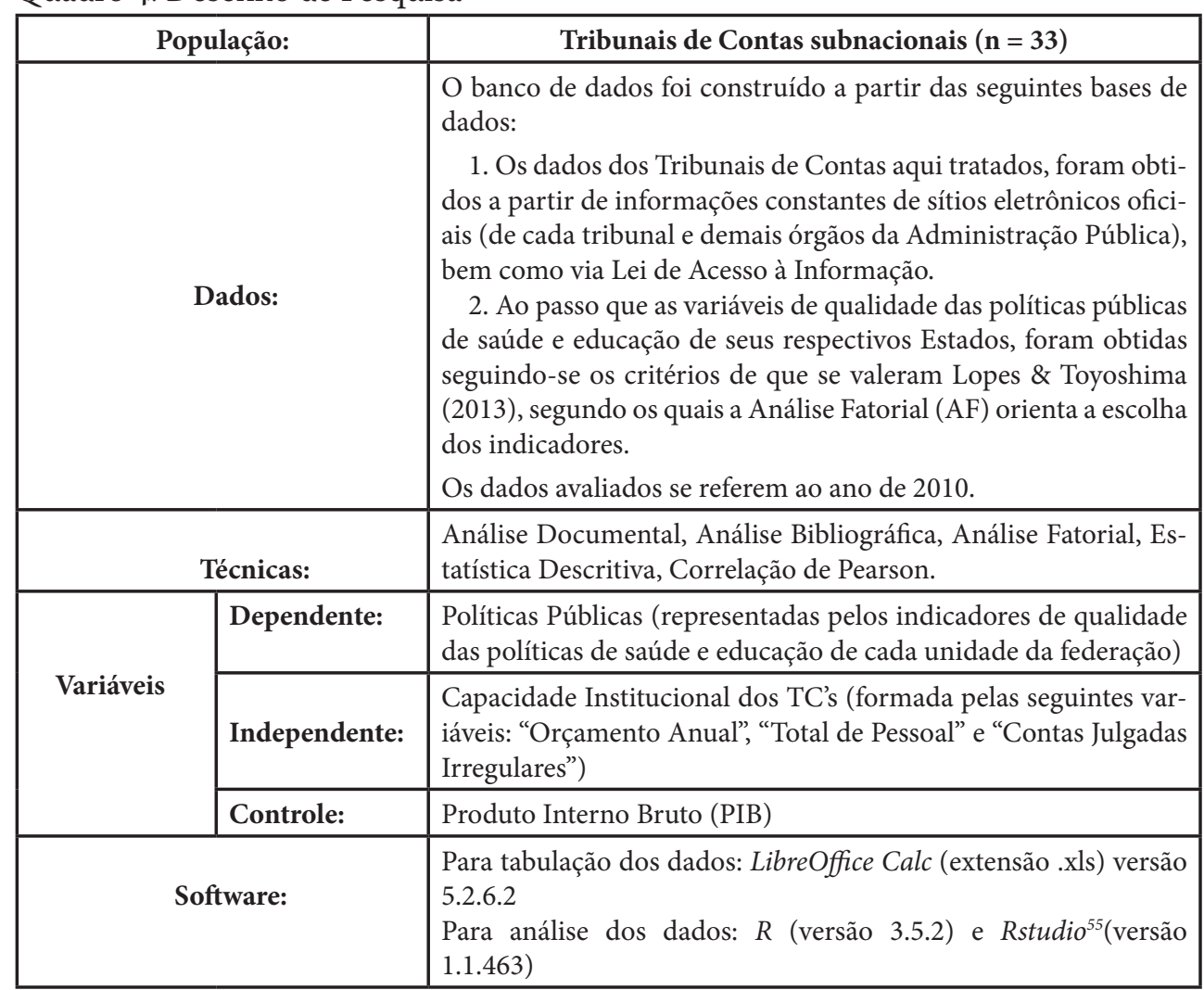

Fonte: Elaboração própria.

54. KING (2005).

55. Destaque-se aqui os principais pacotes utilizados para a análise dos dados, quais sejam: pastecs, lmtest, readxl, UsingR (além dos demais pacotes básicos para utilização do software). 
Os dados utilizados nesta pesquisa foram obtidos por meio do levantamento de informações disponíveis nos sítios eletrônicos oficiais dos órgãos da Administração Pública, bem como por meio do requerimento de informações via Lei de Acesso à Informação - LAI (Lei n $\left.{ }^{\circ} 12.527 / 2011\right)$. A partir de então, construiu-se um banco de dados original composto por 21 (vinte e uma) variáveis, cujas principais informações sobre cada uma delas são sumarizadas no Quadro 5 abaixo:

Quadro 5. Especificações das Variáveis Constantes do Banco de Dados.

\begin{tabular}{|c|c|c|}
\hline VARIÁVEL & $\begin{array}{l}\text { N O M E N - } \\
\text { CLATURA NO } \\
\text { BANCO DE } \\
\quad \text { DADOS }\end{array}$ & DESCRIÇÃO \\
\hline Identificação & id & $\begin{array}{l}\text { Variável que indica as instituições pesquisadas (os Tribunais de Contas sub- } \\
\text { nacionais). }\end{array}$ \\
\hline $\begin{array}{l}\text { Contas } \\
\text { Irregulares }^{56}\end{array}$ & irraccounts & $\begin{array}{l}\text { Variável que indica o total de contas julgadas irregulares pelas instituições } \\
\text { pesquisadas, no ano de } 2010 \text {. }\end{array}$ \\
\hline $\begin{array}{l}\text { Recursos sob } \\
\text { Fiscalização }\end{array}$ & recfisc & $\begin{array}{l}\text { Variável que indica o volume total de recursos (R\$) sob fiscalização das in- } \\
\text { stituições pesquisadas, no ano de } 2010 \text {. }\end{array}$ \\
\hline $\begin{array}{l}\text { Contas Irregu- } \\
\text { lares por volume } \\
\text { Recursos sob } \\
\text { Fiscalização }\end{array}$ & IRACREFI & $\begin{array}{l}\text { Variável obtida a partir divisão entre as variáveis "irraccounts" e "recfisc" } \\
\text { (IRACREFI = irraccounts / recfisc). }\end{array}$ \\
\hline Pessoal $^{58}$ & staff & $\begin{array}{l}\text { Variável que indica o número total de pessoal de cada uma das instituições } \\
\text { pesquisadas, no ano de } 2010 \text {. }\end{array}$ \\
\hline Orçamento ${ }^{59}$ & orc & $\begin{array}{l}\text { Variável que indica o valor total do orçamento }(\mathrm{R} \$ \text { ) aprovado na Lei Orça- } \\
\text { mentária Anual (LOA) para cada uma das instituições pesquisadas, no ano } \\
\text { de } 2010 \text {. }\end{array}$ \\
\hline $\begin{array}{l}\text { Produto Interno } \\
\text { Bruto }^{60}\end{array}$ & PIB & $\begin{array}{l}\text { Variável que indica o valor total do Produto Interno Bruto (PIB) da Unidade } \\
\text { da Federação onde se situa cada uma das instituições pesquisadas, no ano } \\
\text { de } 2010 \text {. }\end{array}$ \\
\hline $\begin{array}{l}\text { Percentual de } \\
\text { Pessoas que } \\
\text { Vivem em } \\
\text { Domicílios com } \\
\text { Banheiro e Água } \\
\text { Encanada }^{61}\end{array}$ & DomicBanh & $\begin{array}{l}\text { Variável que calcula a razão entre a população que vive em domicílios par- } \\
\text { ticulares permanentes com água encanada em, pelo menos, um de seus } \\
\text { cômodos e com banheiro exclusivo e a população total residente em dom- } \\
\text { icílios particulares permanentes, multiplicada por } 100 \text {, no ano de } 2010 \text {. }\end{array}$ \\
\hline $\begin{array}{l}\text { Esperança de } \\
\text { Vida ao Nascer }{ }^{62}\end{array}$ & EsperVida & $\begin{array}{l}\text { Variável que indica o número médio de anos que as pessoas deverão viver a } \\
\text { partir do nascimento, se permanecerem constantes ao longo da vida o nível } \\
\text { e o padrão de mortalidade por idade, prevalecentes no ano do Censo. }\end{array}$ \\
\hline $\begin{array}{l}\text { Taxa de Analfa- } \\
\text { betismo na } \\
\text { Faixa Etária de } \\
11 \text { a } 14 \text { anos }^{63}\end{array}$ & Analf_11_14 & $\begin{array}{l}\text { Variável que calcula a razão entre a população de } 11 \text { a } 14 \text { anos de idade que } \\
\text { não sabe ler nem escrever um bilhete simples e o total de pessoas nesta faixa } \\
\text { etária, multiplicada por } 100 \text {, no ano de } 2010 \text {. }\end{array}$ \\
\hline $\begin{array}{l}\text { Percetual de } \\
\text { Jovens de } 18 \text { a } \\
20 \text { Anos com } \\
\text { Ensino Médio } \\
\text { Completo }^{64}\end{array}$ & MdCmpl18_20 & $\begin{array}{l}\text { Variável que mede a razão entre a população de } 18 \text { a } 20 \text { anos de idade que } \\
\text { já concluiu o ensino médio em quaisquer de suas modalidades (regular se- } \\
\text { riado, não seriado, educação de jovens e adultos ou supletivo) e o total de } \\
\text { pessoas nesta faixa etária multiplicado por } 100 \text {, no ano de } 2010 \text {. }\end{array}$ \\
\hline
\end{tabular}

Fonte: Elaboração própria. 
A hipótese a ser testada - então - será a existência (ou não) de uma relação (ou associação) entre a capacidade institucional dos Tribunais de Contas subnacionais brasileiros e a qualidade das políticas públicas de saúde e educação de seus respectivos Estados.

\section{Métodos e Resultados}

A partir de agora, reportar-se-ão os principais resultados empíricos desta pesquisa. Primeiramente, apresenta-se a estatística descritiva da qualidade das políticas com educação e saúde. As Tabelas 4 e 5 sintetizam a estatística descritiva dos indicadores de qualidade das políticas públicas apuradas:

Tabela 4. Estatística Descritiva - Qualidade das Políticas com Educação e Saúde.

\begin{tabular}{|c|c|c|c|c|}
\hline \multicolumn{1}{|c|}{ Variáveis } & Mínimo & Máximo & Média & Desvio Padrão \\
\hline $\begin{array}{l}\text { Percentual de } \\
\text { Pessoas que } \\
\text { Vivem em Dom- } \\
\text { ić́lios com Ban- } \\
\text { heiro e Água En- } \\
\text { canada (2010) }\end{array}$ & 47,42 & 97,12 & 81,04 & 14,819 \\
\hline $\begin{array}{l}\text { Esperança de } \\
\text { Vida ao Nascer } \\
\text { (2010) }\end{array}$ & 70,32 & 77,35 & 73,51 & 1,825 \\
\hline $\begin{array}{l}\text { Taxa de Analfa- } \\
\text { betismo na Faixa } \\
\text { Etária de 11 a 14 } \\
\text { anos (2010) }\end{array}$ & 1,05 & 8,96 & 3,89 & 2,457 \\
\hline $\begin{array}{l}\text { Percetual de } \\
\text { Jovens de 18 a 20 } \\
\text { Anos com Ensino } \\
\text { Médio Completo } \\
\text { (2010) }\end{array}$ & 24,10 & 53,48 & 38,14 & 8,199 \\
\hline
\end{tabular}

Fonte: Elaboração Própria, a partir de Atlas do Desenvolvimento Humano no Brasil (2010).

56. Os dados relativos a esta variável foram obtidos a partir de consulta ao sítio oficial dos Tribunais Regionais Eleitorais - TREs dos Estados em que se situam cada um dos Tribunais de Contas aqui pesquisados (a partir das informações fornecidas por estes últimos aos TREs).

57. Os dados relativos a esta variável foram obtidos a partir de consulta ao sítio oficial da Secretaria do Tesouro Nacional - STN (<http://www.tesouro.fazenda.gov.br/>).

58. Os dados relativos a esta variável foram obtidos por meio de requerimento de informação junto a cada um dos Tribunais de Contas aqui pesquisados, via Lei de Acesso à Informação.

59. Os dados relativos a esta variável foram obtidos a partir de consulta às Leis Orçamentárias Anuais disponíveis no sítio oficial das Assembleias Legislativas dos Estados em que se situam cada um dos Tribunais de Contas aqui pesquisados (e da Câmara de Vereadores do Rio de Janeiro e de São Paulo). 
Tabela 5. Qualidade das Políticas com Saúde e Educação por Estado.

\begin{tabular}{|c|c|c|c|c|c|c|c|}
\hline \multirow[t]{2}{*}{ Estado } & \multirow[t]{2}{*}{ Região } & \multirow{2}{*}{$\begin{array}{l}\text { Popu- } \\
\text { lação } \\
2010 \\
\text { (mil } \\
\text { habit.) }\end{array}$} & \multirow{2}{*}{$\begin{array}{l}\text { Porcent. } \\
\text { Popu- } \\
\text { lação }\end{array}$} & \multicolumn{2}{|c|}{$\begin{array}{l}\text { Qualidade das Políti- } \\
\text { cas com Saúde }\end{array}$} & \multicolumn{2}{|c|}{$\begin{array}{l}\text { Qualidade das Políti- } \\
\text { cas com Educação }\end{array}$} \\
\hline & & & & $\begin{array}{l}\text { Percent. } \\
\text { pessoas } \\
\text { em dom. } \\
\text { c/ ban- } \\
\text { heiro e } \\
\text { água enc. } \\
(2010)\end{array}$ & $\begin{array}{l}\text { Esper- } \\
\text { ança vida } \\
\text { ao nascer } \\
(2010)\end{array}$ & $\begin{array}{l}\text { Tx. } \\
\text { analfab. } \\
\text { faixa } \\
\text { etária } \\
11 \text { a } 14 \\
(2010)\end{array}$ & $\begin{array}{l}\text { Percent. } \\
\text { Jovens } 18 \\
\text { a } 20 \text { anos } \\
\text { c/ ens. } \\
\text { médio } \\
\text { completo } \\
(2010)\end{array}$ \\
\hline DF & $\mathrm{CO}$ & 2570,20 & 1,30 & 96,01 & 77,35 & 1,10 & 53,48 \\
\hline SC & $S$ & 6248,40 & 3,20 & 97,00 & 76,61 & 1,05 & 51,80 \\
\hline SP & SE & 41262,20 & 21,00 & 97,12 & 75,69 & 1,49 & 52,33 \\
\hline RS & $S$ & 10693,90 & 5,40 & 96,46 & 75,38 & 1,29 & 43,79 \\
\hline MG & SE & 19597,30 & 10,00 & 94,91 & 75,30 & 1,52 & 42,82 \\
\hline ES & SE & 3515,00 & 1,80 & 96,89 & 75,10 & 1,76 & 44,93 \\
\hline $\mathrm{RJ}$ & SE & 15989,90 & 8,10 & 94,73 & 75,10 & 1,76 & 42,93 \\
\hline MS & $\mathrm{CO}$ & 2449,00 & 1,20 & 93,76 & 74,96 & 1,55 & 40,43 \\
\hline $\mathrm{PR}$ & $S$ & 10444,50 & 5,30 & 96,69 & 74,80 & 1,14 & 48,05 \\
\hline GO & $\mathrm{CO}$ & 6003,80 & 3,10 & 93,66 & 74,60 & 1,57 & 44,62 \\
\hline MT & $\mathrm{CO}$ & 3035,10 & 1,50 & 90,37 & 74,25 & 2,00 & 42,36 \\
\hline AP & $\mathrm{N}$ & 669,50 & 0,30 & 66,38 & 73,80 & 3,81 & 35,73 \\
\hline $\mathrm{RR}$ & $\mathrm{N}$ & 450,50 & 0,20 & 74,04 & 73,51 & 5,13 & 40,53 \\
\hline TO & $\mathrm{N}$ & 1383,40 & 0,70 & 80,41 & 72,56 & 2,90 & 40,73 \\
\hline $\mathrm{RO}$ & $\mathrm{N}$ & 1562,40 & 0,80 & 79,62 & 72,97 & 1,59 & 36,47 \\
\hline $\mathrm{RN}$ & $\mathrm{NE}$ & 3168,00 & 1,60 & 85,06 & 72,52 & 6,63 & 36,11 \\
\hline SE & NE & 2068,00 & 1,10 & 82,24 & 71,84 & 5,52 & 30,55 \\
\hline $\mathrm{AM}$ & $\mathrm{N}$ & 3484,00 & 1,80 & 62,16 & 73,30 & 6,54 & 28,76 \\
\hline $\mathrm{CE}$ & $\mathrm{NE}$ & 8452,40 & 4,30 & 76,28 & 72,60 & 4,65 & 37,39 \\
\hline $\mathrm{PA}$ & $\mathrm{N}$ & 7581,10 & 3,90 & 57,50 & 72,36 & 6,32 & 24,10 \\
\hline $\mathrm{PE}$ & $\mathrm{NE}$ & 8796,40 & 4,50 & 78,22 & 72,32 & 5,66 & 32,64 \\
\hline $\mathrm{PB}$ & $\mathrm{NE}$ & 3766,50 & 1,90 & 78,91 & 72,00 & 5,39 & 32,88 \\
\hline $\mathrm{BA}$ & $\mathrm{NE}$ & 14016,90 & 7,10 & 77,60 & 71,97 & 5,01 & 29,49 \\
\hline $\mathrm{AC}$ & $\mathrm{N}$ & 733,60 & 0,40 & 47,42 & 71,63 & 6,64 & 31,98 \\
\hline PI & $\mathrm{NE}$ & 3118,40 & 1,60 & 67,12 & 71,62 & 6,50 & 29,44 \\
\hline MA & $\mathrm{NE}$ & 6574,80 & 3,30 & 51,79 & 70,40 & 7,59 & 29,60 \\
\hline $\mathrm{AL}$ & $\mathrm{NE}$ & 8796,40 & 4,50 & 75,64 & 70,32 & 8,96 & 25,86 \\
\hline
\end{tabular}

Fonte: Elaboração Própria, a partir de Instituto Brasileiro de Geografia e Estatística (IBGE) / Atlas do Desenvolvimento Humano no Brasil (2010). 
Dos 27 Estados, 11 (40\% deles) apresentaram todos os indicadores de qualidade das políticas com saúde e educação acima da média, são eles (em ordem alfabética): Distrito Federal, Espírito Santo, Goiás, Minas Gerais, Mato Grosso, Mato Grosso do Sul, Paraná, Rio de Janeiro, Rio Grande do Sul, Santa Catarina e São Paulo. É possível notar que neste grupo não há nenhum representante das regiões Norte e Nordeste do país. A porcentagem da população anexada por estes estados é de 61,90\%, mais da metade da população total, um fato positivo.

Por outro lado, 10 dos 27 Estados, apresentaram todos os indicadores de saúde e educação abaixo da média, são eles (em ordem alfabética): Acre, Alagoas, Amazonas, Bahia, Ceará, Maranhão, Pará, Paraíba, Pernambuco e Piauí. Todos os Estados deste grupo são das regiões Norte e, principalmente, Nordeste do país. Estes estados concentram uma parcela considerável da população, 33,30\%, porcentagem que não pode ser desconsiderada na formulação de políticas públicas.

Passa-se, neste momento, a analisar os indicadores de capacidade institucional dos Tribunais de Contas subnacionais brasileiros. Para tanto, a Tabela 6 ilustra a estatística descritiva das variáveis.

Tabela 6. Estatística Descritiva - Capacidade Institucional dos Tribunais de Contas Subnacionais.

\begin{tabular}{|l|c|c|c|c|}
\hline \multicolumn{1}{|c|}{ Variável } & Mínimo & Máximo & Média & Desvio Padrão \\
\hline Orçamento (2010) & $27.024 .800,00$ & $455.187 .100,00$ & $125.959 .100,00$ & $103.426 .300,00$ \\
\hline Pessoal (2010) & 85,00 & $2.141,00$ & 608,41 & 453,91 \\
\hline $\begin{array}{l}\text { Contas Irregulares por } \\
\text { Volume de Recursos } \\
\text { sob Fiscalização (2010) }\end{array}$ & 0,0000000001 & 0,0000000392 & 0,0000000064 & 0,0000000104 \\
\hline
\end{tabular}

Fonte: Elaboração própria, a partir da Lei Orçamentária Anual - LOA de cada um dos respectivos Estados / Tribunais de Contas Subnacionais (via Lei de Acesso à Informação) / Secretaria do Tesouro Nacional (STN) / Instituto Brasileiro de Geografia e Estatística (IBGE) / Tribunais Regionais Eleitorais (TREs).

60. Os dados relativos a esta variável foram obtidos a partir de consulta ao sítio oficial do Instituto Brasileiro de Geografia e Estatística - IBGE (<https://www.ibge.gov.br/>).

61. Os dados relativos a esta variável foram obtidos a partir de consulta ao sítio oficial do Atlas do Desenvolvimento Humano no Brasil (<http://atlasbrasil.org.br/>).

62. Os dados relativos a esta variável foram obtidos a partir de consulta ao sítio oficial do Atlas do Desenvolvimento Humano no Brasil (<http://atlasbrasil.org.br/>).

63. Os dados relativos a esta variável foram obtidos a partir de consulta ao sítio oficial do Atlas do Desenvolvimento Humano no Brasil (<http://atlasbrasil.org.br/>).

64. Os dados relativos a esta variável foram obtidos a partir de consulta ao sítio oficial do Atlas do Desenvolvimento Humano no Brasil (<http://atlasbrasil.org.br/>). 
Quanto ao orçamento dos tribunais, a média é de R\$ 125.959.100,oo, com um desvio padrão de 103.426.300,oo. No ano de 2010, o Tribunal de Contas do Estado do Ceará apresentou o menor orçamento, ao passo que o Tribunal de Contas do Estado de São Paulo apresentou o maior orçamento.

Com relação ao quantitativo de pessoal, a média é de 608,41, com um desvio padrão de 453,91. Comparativamente, o Tribunal de Contas do Estado do Amapá apresenta o menor quantitativo de pessoal e o Tribunal de Contas do Estado de São Paulo, por sua vez, possui o maior quantitativo.

É possível notar ainda que, no ano de 2010, a média de contas julgadas irregulares pelos Tribunais de Contas subnacionais foi de aproximadamente 6 para cada R\$ 1.000.000.000,oo sob sua fiscalização, com desvio padrão de o,oooooo0104. O Tribunal de Contas com o maior quantitativo de contas julgadas irregulares por volume de recursos sob sua fiscalização foi o TCE do Acre. Por sua vez, o menor quantitativo de contas julgadas irregulares por volume de recursos sob sua fiscalização foi apresentado pelo TCE de São Paulo.

O próximo procedimento analítico consiste em avaliar a relação entre a capacidade institucional dos Tribunais de Contas subnacionais brasileiros e os indicadores de qualidade das políticas públicas de saúde e educação de seus respectivos Estados. Para tanto, o Gráfico 1 abaixo ilustra o padrão de correlação entre essas variáveis:

Gráfico 1. Correlação entre as Variáveis

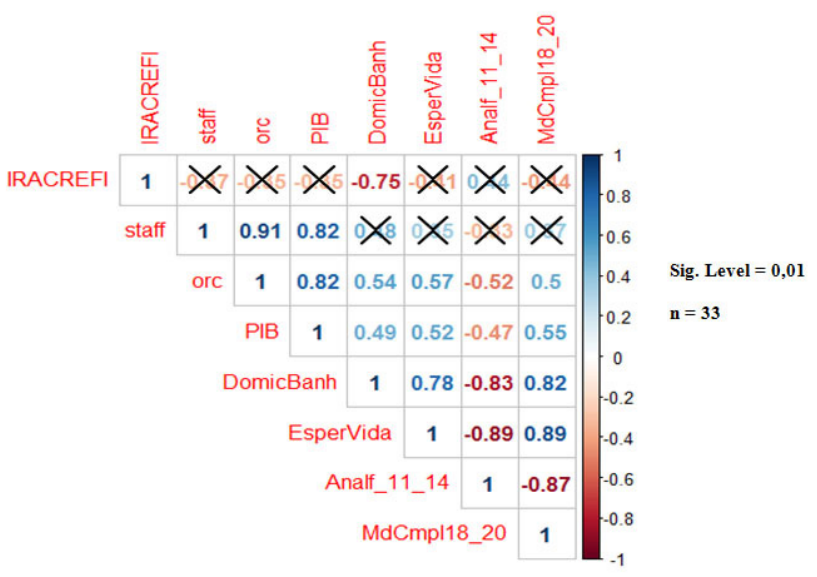

Fonte: Elaboração Própria.

Observa-se uma forte correlação negativa $(r=-0,75)$ e estatisticamente significativa ( $p$-valor $<0,01$ ) entre contas irregulares por volume de recursos sob fiscalização e percentual de pessoas que vivem em domicílios com banheiro e água encanada. Verifica-se, também, uma correlação muito forte, positiva e estatisticamente significativa 
( $\mathrm{p}$-valor $<0,01)$ entre pessoal e orçamento $(\mathrm{r}=0,91)$ e uma forte correlação positiva $\mathrm{e}$ estatisticamente significativa ( $\mathrm{p}$-valor $<\mathrm{o}, \mathrm{o1})$ entre pessoal e PIB $(\mathrm{r}=\mathrm{o}, 82)$.

Quanto à variável orçamento, é possível notar uma forte correlação positiva e estatisticamente significativa ( $\mathrm{p}$-valor $<0,01)$ com a variável PIB $(\mathrm{r}=0,82)$. Verifica-se ainda uma moderada correlação positiva e estatisticamente significativa ( $\mathrm{p}$-valor $<0,01$ ) com as seguintes variáveis: percentual de pessoas que vivem em domicílios com banheiro e água encanada $(r=0,54)$, esperança de vida ao nascer $(r=0,57)$ e percetual de jovens de 18 a 20 anos com ensino médio completo $(\mathrm{r}=0,50)$. Por fim, verifica-se uma moderada correlação negativa e estatisticamente significativa ( $\mathrm{p}$-valor $<0,01)$ com a variável taxa de analfabetismo na faixa etária de 11 a 14 anos $(r=-0,52)$.

A variável PIB possui uma moderada correlação positiva e estatisticamente significativa ( $\mathrm{p}$-valor $<0,01)$ com as seguintes variáveis: esperança de vida ao nascer $(\mathrm{r}$ $=0,52)$ e percetual de jovens de 18 a 20 anos com ensino médio completo $(\mathrm{r}=0,55)$. Verifica-se ainda uma fraca correlação positiva e estatisticamente significativa (p-valor $<0,01$ ) com a variável percentual de pessoas que vivem em domicílios com banheiro e água encanada $(r=0,49)$. Observar-se - também - uma fraca correlação negativa e estatisticamente significativa ( $\mathrm{p}$-valor $<\mathrm{O}, \mathrm{O} 1$ ) com a variável taxa de analfabetismo na faixa etária de 11 a 14 anos $(\mathrm{r}=-0,47)$.

Com relação à variável percentual de pessoas que vivem em domicílios com banheiro e água encanada, é possível notar que ela possui uma forte correlação positiva e estatisticamente significativa ( $\mathrm{p}$-valor $<0,01$ ) com as seguintes variáveis: esperança de vida ao nascer $(\mathrm{r}=0,78)$ e percetual de jovens de 18 a 20 anos com ensino médio completo $(r=0,82)$. Verifica-se ainda uma forte correlação negativa e estatisticamente significativa $(\mathrm{p}$-valor $<0,01)$ com a variável taxa de analfabetismo na faixa etária de 11 a 14 anos $(r=-0,83)$.

A variável esperança de vida ao nascer, por sua vez, possui uma forte correlação positiva e estatisticamente significativa ( $\mathrm{p}$-valor $<\mathrm{O}, 01)$ com a variável percetual de jovens de 18 a 20 anos com ensino médio completo $(\mathrm{r}=0,89)$ e uma forte correlação negativa e estatisticamente significativa ( $\mathrm{p}$-valor $<\mathrm{O}, 01)$ com a variável taxa de analfabetismo na faixa etária de 11 a 14 anos $(\mathrm{r}=-0,89)$. Ao passo que a variável taxa de analfabetismo na faixa etária de 11 a 14 anos possui uma forte correlação negativa e estatisticamente significativa ( $\mathrm{p}$-valor<0,01) com a variável percetual de jovens de 18 a 20 anos com ensino médio completo $(r=-0,87)$. As demais correlações constantes do Gráfico 1 não apresentaram significância estatística (p-valor $>0,01$ ) e, portanto, figuram com um " $\mathrm{X}$ " sobre os seus valores.

Em outras palavras, os resultados aqui reportados sugerem que: o fortalecimento do controle dos gastos públicos está positivamente correlacionado com a qualidade das políticas públicas oferecidas aos cidadãos. Tais resultados sinalizam haver apoio empírico para a hipótese testada neste estudo, isto é, existe uma associação entre a ca- 
pacidade institucional dos Tribunais de Contas subnacionais brasileiros e a qualidade das políticas públicas de saúde e educação de seus respectivos Estados, como destaca Melo et $a l .{ }^{65}$ e Rocha et $a l .{ }^{66} \mathrm{O}$ que reforça a necessidade de um aprofundamento de estudos nessa direção, a fim de ressaltar a importância da atuação dos Tribunais de Contas subnacionais brasileiros em prol da qualidade das políticas públicas.

Contudo, embora esta constatação atenda aos fins a que se destinou o presente artigo, qual seja, encontrar evidências empíricas que sinalizassem na direção da hipótese testada, é importante ressaltar que ela não esgota o assunto. Pelo contrário, ela apenas abre o caminho para novas e aprofundadas discussões sobre o tema, nas quais sejam incluídas análises inferenciais mais robustas e com novas variáveis.

\section{Considerações Finais}

O principal objetivo deste artigo foi analisar a relação entre a capacidade institucional dos Tribunais de Contas subnacionais brasileiros e a qualidade das políticas públicas de seus respectivos Estados.

Metodologicamente, o desenho de pesquisa combinou estatística descritiva e multivariada para analisar um banco de dados original elaborado com informações obtidas de diferentes fontes. Em particular, operacionalizou-se a capacidade institucional dos Tribunais de Contas subnacionais brasileiros a partir das seguintes variáveis: orçamento, pessoal e contas julgadas irregulares. Não obstante, utilizou-se a análise fatorial para definir os indicadores relativos à qualidade das políticas públicas de saúde e educação de seus respectivos Estados, no ano de 2010.

Os resultados preliminares sinalizam haver apoio empírico para a hipótese testada neste estudo: existe uma associação entre a capacidade institucional dos Tribunais de Contas subnacionais brasileiros e a qualidade das políticas públicas de saúde e educação de seus respectivos Estados. Sobretudo porque, analisando os resultados desagregados por variáveis empregadas, observa-se que essa relação é estatisticamente significativa em relação a todas as variáveis empregadas, corroborando a necessidade de novos trabalhos nesta direção que incluam mais variáveis às bases dos indicadores de capacidade institucional dos Tribunais de Contas, permitindo-se assim pesquisas mais robustas e abrangentes.

65. MELO et al. (2009).

66. ROCHA et. al. (2014). 
Em relação às limitações, a principal é a disponibilidade de informações referentes ao tema estudado. Além disso, a análise cross-section diminui a robustez dos resultados em relação a um modelo de dados em painel (por exemplo), que controlaria por variâncias temporais e tornaria a análise menos suscetível a dados fora da média de cada Estado. Por fim, apesar das limitações, o presente trabalho se constitui em esforço para demonstrar que os Tribunais de Contas figuram como importantes instituições de controle, logo, funcionam como checks and balances e, por conseguinte, impactam a qualidade das políticas públicas.

\section{Referencias bibliográficas}

ABRUCIO, Fernando L. y LOUREIRO, Maria R (2004): "Finanças públicas, democracia e accountability: debate teórico e o caso brasileiro". En ARVATE, Paulo R.; BIDERMAN, Ciro. Economia do setor público no Brasil (Rio de Janeiro, Elsevier) pp. 75-102.

ARANTES, Rogério Bastos; ABRUCIO, Fernando Luiz; TEIXEIRA, Marco Antonio Carvalho (2005): "A imagem dos Tribunais de Contas subnacionais". En Revista do Serviço Público, Ano 56, № 1, jan-mar: pp. 57-83.

ARANTES, Rogério; LOUREIRO, Maria Rita; COUTO, Cláudio; TEIXEIRA, Marco Antonio (2011): "Controles democráticos sobre a administração pública no Brasil: Legislativo, Tribunais de Contas, Judiciário e Ministério Público”. En.: LOUREIRO, Maria Rita; ABRUCIO, Fernando; PACHECO, Regina. Burocracia e Política no Brasil Contemporâneo (Rio de Janeiro, Ed. FGV).

BRASIL. Constituição (1988): “Constituição da República Federativa do Brasil”. Brasília, DF, 1988. Disponível em: <http://www.planalto.gov.br>. [Data da pesquisa: 18 de março de 2018].

BRASIL. Ministério do Planejamento, Orçamento e Gestão. Secretaria de Gestão Pública (2014): "Programa GESPÚBLICA, Modelo de Excelência em Gestão Pública" (Brasília, MP, SEGEP).

BRASIL.(2013): “Contrato de Empréstimo 1628/OC-BR_PROMOEX; Relatório Final” (Brasília, MPOG, SEGEP).

BRASIL.(2015): "Programa de Modernização do Sistema de Controle Externo dos Estados e Municípios Brasileiros - PROMOEX” (Brasília, MPOG, SEGEP). 
CAVALCANTE, Mônica Clark Nunes; PETER, Maria da Glória Arrais; MACHADO, Marcus Vinicius Veras (2012): “Controle como Dimensão da Governança Pública: Princípios e Melhores Práticas definidos pelos Órgãos Internacionais”. En VI Congresso de Costos Del MERCOSUR, 2012, Uruguai. Disponível em: < http://website. acep.org.br/2011/wp-content/uploads/2014/10/teste1.pdf $>$. [Data da pesquisa: 18 de agosto de 2018].

CRUZ JUNIOR, Brauner Geraldo (2015): "A Efetividade dos Tribunais de Contas na Fiscalização de Recursos Estaduais e Municipais: Uma Análise dos Tribunais de Contas com base nas irregularidades relatadas em gestões municipais auditadas pela CGU”. 2015. 91 Páginas. Relatório Final projeto de Iniciação Científica - PIBIC Escola de Administração de Empresas de São Paulo (São Paulo, Fundação Getúlio Vargas).

FARACO, Bruno Pereira; NIWA, Tiago Hideki; VICENTIN, Ivan Carlos (2016): "Controle na Administração Pública”. En OLIVEIRA, Antonio Gonçalves; PISA, Beatriz Jackiu; AUGUSTINHO, Sonia Maria (Org.). Gestão e governança pública: aspectos essenciais (Curitiba, Ed. UTFPR).

FERNANDES, Fabiana Silva (2016): "Capacidade institucional: uma revisão de conceitos e programas federais de governo para o fortalecimento da administração pública”. En Cad. EBAPE.BR, Ano 14, No3, Artigo 2, Rio de Janeiro, Jul./Set.

FERREIRA, Thiago Augusto de O. M (2012): "O papel do Tribunal de Contas da União como órgão de avaliação de políticas públicas”. En Revista Jus Navigandi, ISSN 1518-4862, Teresina, ano 17, n. 3136, 1 fev. Disponível em: <https://jus.com. br/artigos/20989>. [Data da pesquisa: 18 de março de 2018].

FERREIRA, Thiago Augusto de O. M (2013): "Arranjos institucionais dos tribunais de contas da União e de Portugal”. 2013. 83 Páginas. Dissertação (Mestrado em Ciência Política) - Programa de Pós-Graduação em Ciência Política (Recife, Universidade Federal de Pernambuco - UFPE).

FIGUEIRÊDO, Carlos Maurício Cabral (2007): "Prestação de contas e responsabilização: uma oportunidade de interação entre os tribunais de contas e o cidadão". En V CONFERÊNCIA EUROSAI-OLACEFS, Lisboa.

FIGUEIREDO FILHO, Dalson Brito et al. (2014): "Análise fatorial garantida ou o seu dinheiro de volta: uma introdução à redução de dados". En Revista Eletrônica de Ciência Política, Ano $5, \mathrm{~N}^{\circ} 2$.

FUKUYAMA, Francis (2005): “Construção de Estados: governo e organização mundial no século XXI” (Rio de Janeiro, Rocco). 
GIL, Antônio Carlos (1999): “Métodos e técnicas de pesquisa social”. 5.ed. (São Paulo, Atlas).

KING, Gary (1995): "Replication, Replication”. En Political Science and Politics, Cambridge, UK, No 28 , set, pp. 443-499.

LOPES, Luckas Sabioni y TOYOSHIMA, Silvia Harumi (2013): "Evidências do Impacto da Corrupção sobre a Eficiência das Políticas de Saúde e Educação nos Estados Brasileiros”. En Planejamento e Políticas Públicas, No 41 jul-dez: pp. 209-238.

LOUREIRO, Maria Rita, TEIXEIRA, Marco Antonio Carvalho, MORAES, Tiago Cacique (2009): "Democratização e reforma do Estado: o desenvolvimento institucional dos tribunais de contas no Brasil recente”. En Revista de Administração Pública, Ano 43 No4, jul-ago: pp. 739-772.

MELO, Marcus André (2008): “O controle externo na América Latina”. (São Paulo, Instituto Fernando Henrique Cardoso; Santiago do Chile, Corporación de Estudios para Latinoamérica - Cieplan), 56 p. Contribuição ao projeto: Uma Nova Agenda Econômica e Social para a América Latina. Disponível em: <http://www. ifhc.org.b r/>. [Data da pesquisa: 18 de março de 2018].

MELO, Marcus André; PEREIRA, Carlos; FIGUEIREDO, Carlos Maurício Cabral (2009): "Political and Institutional Checks on Corruption: Explaining the Performance of Brazilian Audit Institutions". En Comparative Political Studies, Ano 42, No 9, Michigan, Set.

MORAES, Tiago Cacique (2006): "O Processo de Modernização dos Tribunais de Contas no Contexto da Reforma do Estado no Brasil”. 113 páginas. Mestrado em Administração Pública e Governo. Escola de Administração de Empresas de São Paulo (São Paulo, Fundação Getúlio Vargas).

O'DONNELL, Guillermo (1998): “Accountability horizontal e novas poliarquias”. En Lua Nova, São Paulo, n. 44. Disponível em <http://www.scielo.br/scielo.php? script $=$ sci_arttext\&pid=So102-64451998000200003\&lng $=$ pt\&nrm $=$ iso $>$. [Data da pesquisa: 18 de março de 2018].

OLIVEIRA, Alden Mangueira de (2015): “Governança no Setor Público sob o Prisma do Controle Externo: a experiência do Tribunal de Contas da União (TCU) na avaliação das políticas públicas e na indução do seu aperfeiçoamento como alavanca ao Desenvolvimento Nacional”. 2015. pp. 178. Curso de Altos Estudos de Política e Estratégia. Departamento de Estudos (Rio de Janeiro, Escola Superior de Guerra). 
PASSARINHO, Nathalia (2018): “Os ministérios mais cobiçados pelos políticos do Brasil, segundo pesquisa inédita de Oxford”. En BBC Brasil. Disponível em: <http://www.bbc.com/portuguese/brasil-43218087>. [Data da pesquisa: $18 \mathrm{de}$ março de 2018].

ROCHA, Enivaldo Carvalho da et al. (2014): "Capacidade institucional e corrupção: Tribunais de Contas Estaduais em perspectiva comparada”. En Revista Debates, Porto Alegre, Ano 8, No 3, set.-dez, pp. 181-204.

SANO, Hironobu y MONTENEGRO FILHO, Mário Jorge França (2013): "As Técnicas de Avaliação da Eficiência, Eficácia e Efetividade na Gestão Pública e sua Relevância para o Desenvolvimento Social e das Ações Públicas". En Desenvolvimento em Questão, Editora Unijuí, Ano 11, No 22, jan./abr.

SPECK, Bruno Wilhelm (200o): "Inovação e rotina no Tribunal de Contas da União: o papel da instituição superior de controle financeiro no sistema político-administrativo do Brasil”. (São Paulo, Função Konrad Adenauer).

SPECK, Bruno Wilhelm (2013): “Tribunais de Contas”. En Revista Gestão e Controle, No 1, pp. 211-219.

STAPENHURST, Rick y TITSWORTH, Jack (2001): "Features and functions of supreme audit institutions: Supreme audit institutions can curb corruption by reinforcing legal, financial, and institutional frameworks and by reducing the arbitrary application of rules and laws". En Notes Public Sector, No 59 , World Bank.

TEIXEIRA, Marco Antônio Carvalho y ALVES, Márcio Aquino (2011): "Ethos organizacional e controle da corrupção: o TCU sob uma ótica organizacional”. En Cadernos Adenauer, Fundação Konrad Adenauer, Rio de Janeiro, Ano 12, No 3, pp. 75-109. 